\title{
Nonlinear Chaotic Signals Generation and Transmission within an Optical Fiber Communication Link
}

\author{
I. S. Amiri ${ }^{1 *}$, A. Nikoukar ${ }^{2}$, J. Ali $^{1}$ \\ ${ }^{1}$ Institute of Advanced Photonics Science, Nanotechnology Research Alliance, Universiti Teknologi Malaysia \\ (UTM), 81310 Johor Bahru, Malaysia \\ ${ }^{2}$ Faculty of Computer Science \& Information Systems (FCSIS), Universiti Teknologi Malaysia (UTM), 81300 \\ Johor Bahru, Malaysia
}

\begin{abstract}
The nonlinear behavior of light such as chaos traveling in an optical fiber ring resonator as a single ring resonator is presented. This phenomenon can be used to generate secret codes or arbitrary digital codes of " 0 " and " 1 " applicable in the communication system such as time division multiple access (TDMA) system. Such a system can be used to secure the information signals therefore, the ability of chaotic carriers to synchronize in a communication system is performed. The used optical material is InGaAsP/InP regarding to suitable parameters of the system. The nonlinear refractive index is fixed to $n_{2}=3.8 \times 10^{-20} \mathrm{~m}^{2} / \mathrm{W}$. The input power is selected at $1 \mathrm{~W}$, where the coupling coefficient of the system varies as $0<\kappa<0.1$. As a result, train of logic codes could be generated and transmitted via a fiber communication link using the chaotic signals. To optimize the microring systems, Lower input power is recommended in many applications in optical optical communication systems
\end{abstract}

Keywords: Chaotic communication; Logic Codes; TDMA system; Optical Soliton Transmission

\section{Introduction}

Nonlinear behaviors of light traveling in a fiber optic ring resonator are commonly induced by the effects such as Kerr effects [1-4], four-wave mixing, and the external nonlinear pumping power [5]. Such nonlinear behaviors are named as chaos, bistability, and bifurcation [6]. More details of such behaviors in a microring resonator are clearly described by Amiri et al [7]. However, apart from the penalties of the nonlinear behaviors of light traveling in the fiber ring resonator [8-9], there are some benefits that can be used in the communication system [10]. One of them known as chaotic behavior that has been used to make the benefit of communication system in either electronic or optical communications [11-13]. Fortunately, most of the previous investigations are shown in mathematical ways, where the practical applications could be implemented [14-16]. For instance, the chaotic control input power [17-20] into the system is equal to the standard communication light source used in the system, and the implemented fiber optic devices are in the fabrication scales [21-23]. This means the ability of chaotic carriers to synchronize in a communication system is valid [24-26]. Recently, Amiri et al. have reported the successful characterization of the microring resonator with a radius of micron meters [27-28] using the optical materials called InGaAsP/InP [29-31], which are suitable for use in the practical devices and systems [32-33].

Amiri et al have also shown that an add/drop device could be constructed using a microring resonator, where the device characteristics have shown that they are suitable to implement in the practical communication system [34-35]. In practical applications, the microring resonator and add/drop device parameters are required to make them within the ranges of the usual fabrication parameters [36-39]. This paper presents the design of the system of the chaotic signal generation that uses the practical device parameters. Such a system can be used to secure the information signals [40-41], where the tapping of the signals from the optical communication link is extremely difficult [42-44]. The results obtained have shown that the device parameters used have good potentials for practical applications. The analogy of the chaotic signal generation using fiber ring resonator and the related behaviors is described. This research is supported by the Institute of Advanced Photonics Science, Nanotechnology Research Alliance, Universiti Teknologi Malaysia (UTM).

\section{THEORY AND SYSTEM}

A ring resonator configuration is shown in figure 1, where the circumference of the fiber ring is $L$ [4548]. The input and output signals are given by $E_{\text {in }}$ and $E_{\text {out }}$ respectively. 


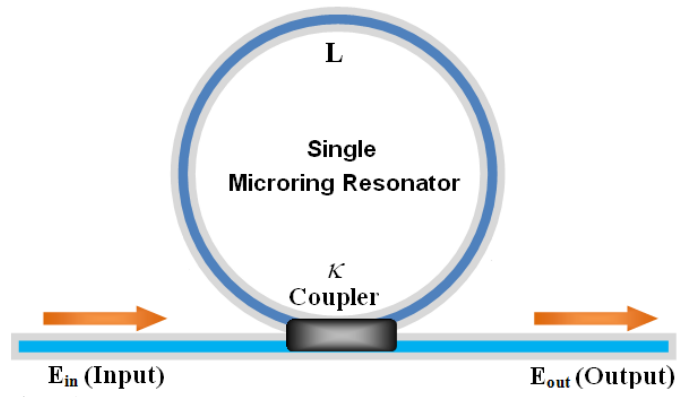

Fig. 1: A diagram of a fiber optic ring resonator

Here, the input light of the monochromatic diode laser is inserted into the system [49-54]. The input light of Gaussian beams can be expressed as [55-59],

$E_{i n}(t)=E_{0} \exp \left[\left(\frac{x}{2 L_{D}}\right)-i \omega_{0} t\right]$

$E_{0}$ and $x$ are the amplitude of optical field and propagation distance respectively [60-63]. $L_{D}$ is the dispersion length of the soliton pulse [64-67] where, frequency shift of the signal is $\omega_{0}$ [68-70]. When a soliton pulse is input and propagated within a microring resonator, the resonant output is formed, thus, optical circuits of the system can be given by [71-73],

$\left|\frac{E_{\text {out }}(t)}{E_{\text {in }}(t)}\right|^{2}=(1-\gamma)\left[1-\frac{\left(1-(1-\gamma) x^{2}\right) \kappa}{(1-x \sqrt{1-\gamma} \sqrt{1-\kappa})^{2}+4 x \sqrt{1-\gamma} \sqrt{1-\kappa} \sin ^{2}\left(\frac{\phi}{2}\right)}\right]$

$\kappa$ is the coupling coefficient [74], and $x=\exp (-\alpha L / 2)$ represents a round-trip loss coefficient [75], $\Phi_{0}=k L n_{0}$ [76] and $\Phi_{\mathrm{NL}}=k L n_{2}\left|E_{\mathrm{in}}\right|^{2}$ are the linear and nonlinear phase shifts [77-78] and $k=2 \pi / \lambda$ is the wave propagation number in a vacuum [79]. $L$ and $\alpha$ are a waveguide length and linear absorption coefficient, respectively [80-82]. The parameters of the system were fixed to be $\lambda_{0}=1.55 \mu \mathrm{m}, n_{0}=3.34$ [83-85], $A_{\text {eff }}$ is the effective mode core area of the fiber [86-88], where $A_{\text {eff }}=30 \mu \mathrm{m}^{2}$, the fiber losses $\alpha=0.02 \mathrm{~dB} / \mathrm{km}$ [89-90]. The fractional coupler intensity loss is $\gamma=0.01$ [91-92], and $R=12.5 \mu \mathrm{m}$. The coupling coefficient varies regarding to the input power [93-94]. The nonlinear refractive indices ranged from $n_{2}=3.8 \times 10^{-20} \mathrm{~m}^{2} / \mathrm{W}$, and the 20,000 iterations of round-trips inside the optical fiber is simulated [95].

\section{Results And Discussion}

The input power is maximized at $1 \mathrm{~W}$, where the output power is varied directly with the coupling coefficient. Thus, the chaotic signal can be generated and controlled by varying the coupling coefficients, where the required output power is obtained. Here, the coupling coefficient ranges as $0<\kappa<0.1$. Figure 2 shows the output chaotic signals generated for a variety of coupling coefficients, where the coupling coefficients vary from $\kappa=0.02$ to $\kappa=0.085$. The figure 2 (a) shows the output signal in terms of round-trip, where the figure 2(b-e) show the output signals reverence to different coupling coefficients. Therefore, larger coupler coefficient corresponds to lower input power which is required in many applications in optical switching and optical communication systems.

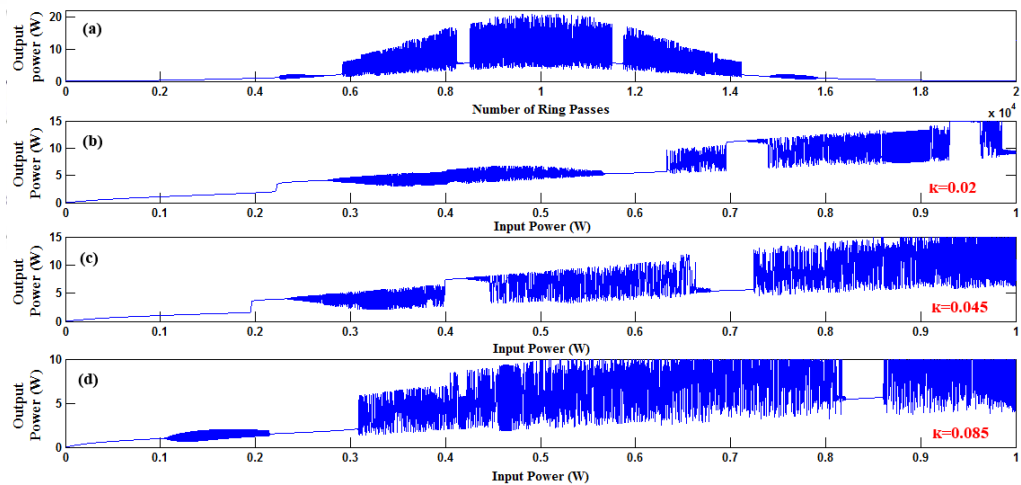

Fig. 2: Generation of chaotic signals when $0<\kappa<0.1$, (a): output signal versus number of round-trips, (b): Output chaotic signal where $\kappa=0.02$, (c): Output chaotic signal where $\kappa=0.045$, (d): Output chaotic signal where $\kappa=0.085$ 
The chaotic signals can be used to generate information of binary codes where the encoding and decoding of data can be performed via a TDMA system. This system will encode the binary logic codes of " 0 " and "1" and transmit them via fiber optic communication, where the decoding process is performed at the end of the transmission link. The schematic of the TDMA system is shown in figure 3, in which transmission of chaotic signals for communication networks can be obtained. Thus by using arbitrary digital coding, different signal information propagate in the network communication via a TDMA transmission system. This system uses data in the form of secured codes to be transferred to single users via different lengths of the fiber optic line to the TDMA transmitter.

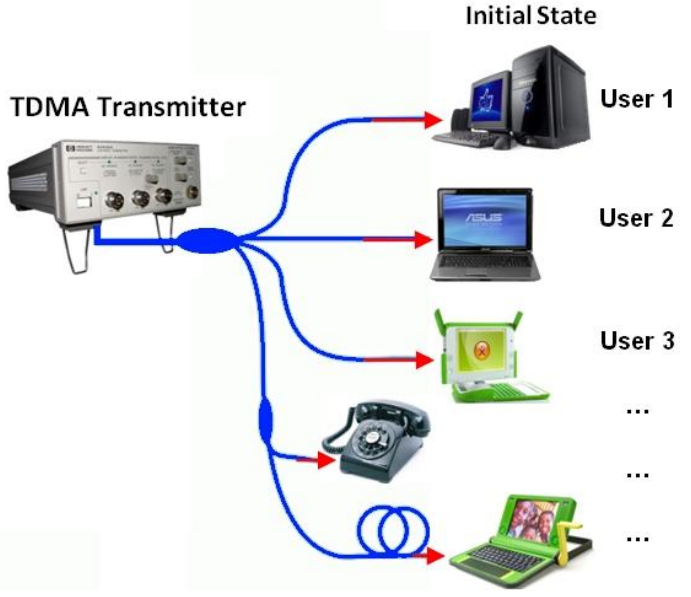

Fig. 3: Schematic of the TDMA system

Therefore, digital code information can be shared between users in different time slots. The transmission unit is a part of the quantum processing system that can be used to transfer the high capacity packet of quantum codes. Moreover, a high capacity of data can be transferred by using more wavelength carriers. Here, transmission of arbitrary digital codes of "1111000000101001111000000000000011000000000001" is performed. Figure 4 shows the forms of transmitting signals in the optical fiber communication system.
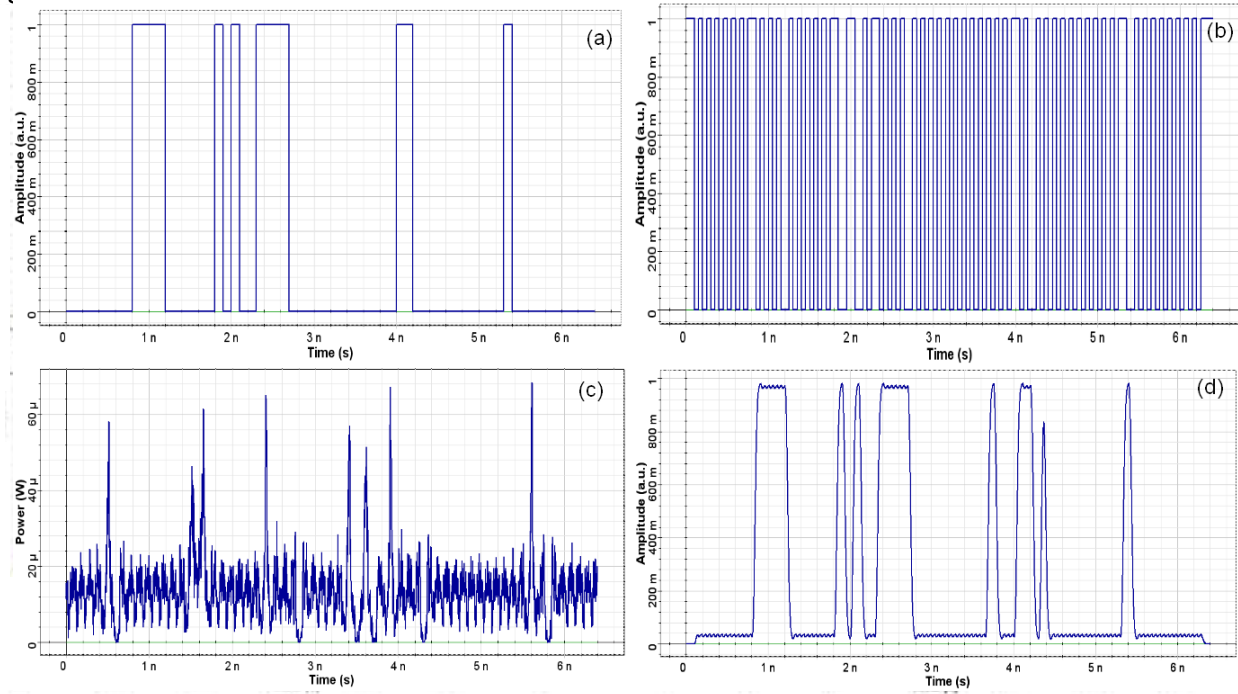

Fig. 4: Transmitting of digital codes where (a): Binary codes, (b): Secured codes, (c), Transmitted codes over 125 $\mathrm{km}$ fiber optics, (d) decoded signals into original signals.

Therefore, transmission of data along fiber network communication is performed using chaotic signals. The security scheme of the transmission can be obtained by encoding-decoding of data where the high capacity of transmission requires highly optical signals such as chaotic signal which is employed whether it is used as optical carrier or optical information.

\section{Conclusion}

We have proposed the optical microring resonator system that uses critical parameters such as coupling coefficient to generate and control the output signals in the form of chaotic signals. Here, the common nonlinear penalty in the fiber optic microring resonator is presented. By using the chaotic signal generation system, the information or data, in an optical communication and transmission link can be secured and used for a public 
network. The chaotic signals can be encoded and decoded within a communication network system such as a TDMA system. Therefore secret codes travel within the optical fiber communication, where the detection of the signals can be performed using the TDMA system. This technique is used to transfer the information along long distance fiber communication which is a promising application in nano digital communication especially when a soliton pulse is employed.

\section{Acknowledgements}

I. S. Amiri would like to thank the Institute of Advanced Photonics Science, Nanotechnology Research Alliance, Universiti Teknologi Malaysia (UTM).

\section{REFERENCES}

[1] I. S. Amiri, A. Afroozeh, M. Bahadoran, J. Ali, and P. P. Yupapin, Molecular Transporter System for Qubits Generation, Jurnal Teknologi (Sciences and Engineering), 55, 2012, 155-165.

[2] A. Afroozeh, M. Bahadoran, I. S. Amiri, A. R. Samavati, J. Ali, and P. P. Yupapin, Fast Light Generation Using GaAlAs/GaAs Waveguide, Jurnal Teknologi (Sciences and Engineering), 57, 2012, 17-23.

[3] J. Ali, I. S. Amiri, M. A. Jalil, M. Hamdi, F. K. Mohamad, N. J. Ridha, and P. P. Yupapin, Trapping spatial and temporal soliton system for entangled photon encoding, presented at the Nanotech Malaysia, International Conference on Enabling Science \& Technology, Kuala Lumpur, Malaysia, 2010.

[4] I. S. Amiri, A. Shahidinejad, A. Nikoukar, J. Ali, and P. Yupapin, A Study oF Dynamic Optical Tweezers Generation For Communication Networks, International Journal of Advances in Engineering \& Technology (IJAET), 4(2), 2012, 38-45.

[5] I. S. Amiri, M. Ranjbar, A. Nikoukar, A. Shahidinejad, J. Ali, and P. Yupapin, Multi optical Soliton generated by PANDA ring resonator for secure network communication, in Computer and Communication Engineering (ICCCE) Conference, Malaysia, 2012, 760-764.

[6] J. Ali, M. Kouhnavard, I. S. Amiri, M. A. Jalil, A. Afroozeh, and P. P. Yupapin Security confirmation using temporal dark and bright soliton via nonlinear system, presented at the ICAMN, International Conference, Prince Hotel, Kuala Lumpur, Malaysia, 2010.

[7] I. S. Amiri, R. Ahsan, A. Shahidinejad, J. Ali, and P. P. Yupapin, Characterisation of bifurcation and chaos in silicon microring resonator, IET Communications, 6(16), 2012, 2671-2675.

[8] J. Ali, K. Kulsirirat, W. Techithdeera, M. A. Jalil, I. S. Amiri, I. Naim, and P. P. Yupapin, Temporal dark soliton behavior within multi-ring resonators, presented at the Nanotech Malaysia, International Conference on Enabling Science \& Technology, Malaysia 2010

[9] I. S. Amiri, A. Nikoukar, A. Shahidinejad, J. Ali, and P. Yupapin, Generation of discrete frequency and wavelength for secured computer networks system using integrated ring resonators, in Computer and Communication Engineering (ICCCE) Conference, Malaysia, 2012, 775-778.

[10] I. S. Amiri, J. Ali, and P. Yupapin, Security Enhancement of the Optical Signal Communication using Binary Codes Generated by Optical Tweezers, Chinese Journal of Physics, 2013.

[11] J. Ali, A. Afroozeh, I. S. Amiri, M. A. Jalil, M. Kouhnavard, and P. P. Yupapin, Generation of continuous optical spectrum by soliton into a nano-waveguide, presented at the ICAMN, International Conference, Prince Hotel, Kuala Lumpur, Malaysia, 2010.

[12] J. Ali, M. A. Jalil, I. S. Amiri, and P. P. Yupapin, MRR quantum dense coding, presented at the Nanotech Malaysia, International Conference on Enabling Science \& Technology, KLCC, Kuala Lumpur, Malaysia 2010.

[13] J. Ali, A. Afroozeh, M. Hamdi, I. S. Amiri, M. A. Jalil, M. Kouhnavard, and P. Yupapin, Optical bistability behaviour in a doublecoupler ring resonator, presented at the ICAMN, International Conference, Prince Hotel, Kuala Lumpur, Malaysia, 2010.

[14] J. Ali, K. Raman, A. Afroozeh, I. S. Amiri, M. A. Jalil, I. N. Nawi, and P. P. Yupapin, Generation of DSA for security application, presented at the 2nd International Science, Social Science, Engineering Energy Conference (I-SEEC 2010), Nakhonphanom, Thailand, 2010

[15] P. P. Yupapin, M. A. Jalil, I. S. Amiri, I. Naim, and J. Ali, New Communication Bands Generated by Using a Soliton Pulse within a Resonator System, Circuits and Systems, 1(2), 2010, 71-75.

[16] M. Kouhnavard, I. S. Amiri, M. Jalil, A. Afroozeh, J. Ali, and P. P. Yupapin, QKD via a quantum wavelength router using spatial soliton, in Enabling Science and Nanotechnology (ESciNano) Conference, Malaysia, 2010, 210-216.

[17] J. Ali, S. Saktioto, M. Hamdi, and I. S. Amiri, Dynamic silicon dioxide fiber coupling polarized by voltage breakdown, presented at the Nanotech Malaysia, International Conference on Enabling Science \& Technology, Kuala Lumpur, Malaysia, 2010.

[18] M. A. Jalil, I. S. Amiri, M. Kouhnavard, A. Afroozeh, J. Ali, and P. P. Yupapin, Finesse Improvements of Light Pulses within MRR System, in Faculty of Science Postgraduate Conference (FSPGC), Universiti Teknologi Malaysia, 2010.

[19] N. J. Ridha, F. K. Mohamad, I. S. Amiri, Saktioto, J. Ali, and P. P. Yupapin, Controlling Center Wavelength and Free Spectrum Range by MRR Radii presented at the International Conference on Experimental Mechanics (ICEM), Kuala Lumpur, Malaysia, 2010

[20] A. A. Shojaei and I. S. Amiri, DSA for Secured Optical Communication, presented at the International Conference for Nanomaterials Synthesis and Characterization (INSC), Kuala Lumpur, Malaysia, 2011.

[21] M. Imran, R. A. Rahman, and I. S. Amiri, Fabrication of Diffractive Optical Element using Direct Writing CO2 Laser Irradiation, in Faculty of Science Postgraduate Conference (FSPGC), Universiti Teknologi Malaysia, 2010

[22] S. Saktioto, S. Daud, M. A. Jalil, I. S. Amiri, and P. P. Yupapin, FBG sensing system for outdoor temperature measurement, presented at the ICEM, Legend Hotel, Kuala Lumpur, Malaysia, 2010.

[23] A. Shahidinejad, A. Nikoukar, I. S. Amiri, M. Ranjbar, A. Shojaei, J. Ali, and P. Yupapin, Network system engineering by controlling the chaotic signals using silicon micro ring resonator, in Computer and Communication Engineering (ICCCE) Conference, Malaysia, 2012, 765-769.

[24] J. Ali, I. S. Amiri, M. A. Jalil, A. Afroozeh, M. Kouhnavard, and P. Yupapin, Novel system of fast and slow light generation using micro and nano ring resonators, presented at the ICAMN, International Conference, Prince Hotel, Kuala Lumpur, Malaysia, 2010.

[25] I. S. Amiri, G. Vahedi, A. Shojaei, A. Nikoukar, J. Ali, and P. P. Yupapin, Secured Transportation of Quantum Codes Using Integrated PANDA-Add/drop and TDMA Systems, International Journal of Engineering Research \& Technology (IJERT), 1(5). 2012 .

[26] M. Kouhnavard, A. Afroozeh, I. S. Amiri, M. A. Jalil, J. Ali, and P. P. Yupapin, New system of Chaotic Signal Generation Using MRR, presented at the International Conference on Experimental Mechanics (ICEM), Kuala Lumpur, Malaysia, 2010. 
[27] I. S. Amiri, A. Afroozeh, and M. Bahadoran, Simulation and Analysis of Multisoliton Generation Using a PANDA Ring Resonator System, Chinese Physics Letters, 28, 2011, 104205.

[28] I. S. Amiri, A. Nikoukar, A. Shahidinejad, M. Ranjbar, J. Ali, and P. P. Yupapin, Generation of Quantum Photon Information Using Extremely Narrow Optical Tweezers for Computer Network Communication, GSTF Journal on Computing (joc), $2(1), 2012$.

[29] A. Afroozeh, I. S. Amiri, M. Kouhnavard, M. Bahadoran, M. A. Jalil, J. Ali, and P. P. Yupapin, Dark and Bright Soliton trapping using NMRR, presented at the International Conference on Experimental Mechanics (ICEM), Kuala Lumpur, Malaysia, 2010.

[30] J. Ali, A. Mohamad, I. Nawi, I. S. Amiri, M. Jalil, A. Afroozeh, and P. Yupapin, Stopping a dark soliton pulse within an NNRR, presented at the $A M N-A P L O C$ International Conference, Wuhan, China 2010.

[31] S. Saktioto, S. Daud, J. Ali, M. A. Jalil, I. S. Amiri, and P. P. Yupapin, FBG simulation and experimental temperature measurement, presented at the ICEM, Legend Hotel, Kuala Lumpur, Malaysia, 2010.

[32] I. S. Amiri, M. H. Khanmirzaei, M. Kouhnavard, and S. Mitatha, Quantum cryptography via a wavelength router for internet security, Piers Proceeding, Cambridge, 2010.

[33] I. S. Amiri, M. Nikmaram, A. Shahidinejad, and J. Ali, Cryptography Scheme of an Optical Switching System Using Pico/Femto Second Soliton Pulse, International Journal of Advances in Engineering \& Technology (IJAET), 5(1), 2012, $176-184$.

[34] I. S. Amiri, J. Ali, and P. P. Yupapin, Enhancement of FSR and Finesse Using Add/Drop Filter and PANDA Ring Resonator Systems, International Journal of Modern Physics B, 26(04), 2012.

[35] I. S. Amiri, S. Babakhani, G. Vahedi, J. Ali, and P. Yupapin, Dark-Bright Solitons Conversion System for Secured and Long Distance Optical Communication, IOSR Journal of Applied Physics (IOSR-JAP), 2(1), 2012, 43-48.

[36] A. Afroozeh, I. S. Amiri, M. Kouhnavard, M. Bahadoran, M. A. Jalil, J. Ali, and P. P. Yupapin, Optical Memory Time using Multi Bright Soliton, presented at the International Conference on Experimental Mechanics (ICEM), Kuala Lumpur, Malaysia, 2010.

[37] J. Ali, I. S. Amiri, M. Jalil, M. Kouhnavard, A. Afroozeh, I. Naim, and P. Yupapin, Narrow UV pulse generation using MRR and NRR system, presented at the ICAMN, International Conference, Prince Hotel, Kuala Lumpur, Malaysia, 2010.

[38] J. Ali, M. Kouhnavard, A. Afroozeh, I. S. Amiri, M. A. Jalil, and P. P. Yupapin, Optical bistability in a FORR, presented at the ICEM, Legend Hotel, Kuala Lumpur, Malaysia, 2010.

[39] A. A. Shojaei and I. S. Amiri, Soliton for Radio wave generation, presented at the International Conference for Nanomaterials Synthesis and Characterization (INSC), Kuala Lumpur, Malaysia, 2011.

[40] I. S. Amiri, A. Afroozeh, J. Ali, and P. P. Yupapin, Generation Of Quantum Codes Using Up And Down Link Optical Solition, Jurnal Teknologi (Sciences and Engineering), 55, 2012, 97-106.

[41] J. Ali, M. Kouhnavard, M. A. Jalil, and I. S. Amiri, Quantum signal processing via an optical potential well, presented at the Nanotech Malaysia, International Conference on Enabling Science \& Technology, Kuala Lumpur, Malaysia 2010.

[42] I. S. Amiri, M. A. Jalil, A. Afroozeh, M. Kouhnavard, J. Ali, and P. P. Yupapin, Controlling Center Wavelength and Free Spectrum Range by MRR Radii, in Faculty of Science Postgraduate Conference (FSPGC), Universiti Teknologi Malaysia, 2010.

[43] J. Ali, A. Afroozeh, I. S. Amiri, M. A. Jalil, and P. P. Yupapin, Dark and Bright Soliton trapping using NMRR, presented at the ICEM, Legend Hotel, Kuala Lumpur, Malaysia, 2010.

[44] I. S. Amiri, A. Nikoukar, G. Vahedi, A. Shojaei, J. Ali, and P. Yupapin, Frequency-Wavelength Trapping by Integrated Ring Resonators For Secured Network and Communication Systems, International Journal of Engineering Research \& Technology (IJERT), 1(5), 2012

[45] J. Ali, M. A. Jalil, I. S. Amiri, and P. P. Yupapin, Dark-bright solitons conversion system via an add/drop filter for signal security application, presented at the ICEM, Legend Hotel, Kuala Lumpur, Malaysia, 2010.

[46] I. S. Amiri, A. Shahidinejad, A. Nikoukar, M. Ranjbar, J. Ali, and P. P. Yupapin, Digital Binary Codes Transmission via TDMA Networks Communication System Using Dark and Bright Optical Soliton, GSTF Journal on Computing (joc), 2(1), 2012.

[47] J. Ali, M. Roslan, M. Jalil, I. S. Amiri, A. Afroozeh, I. Nawi, and P. Yupapin, DWDM enhancement in micro and nano waveguide, presented at the AMN-APLOC International Conference, Wuhan, China, 2010.

[48] I. S. Amiri, K. Raman, A. Afroozeh, M. A. Jalil, I. N. Nawi, J. Ali, and P. P. Yupapin, Generation of DSA for security application, Procedia Engineering, 8, 2011, 360-365.

[49] A. Afroozeh, I. S. Amiri, M. A. Jalil, M. Kouhnavard, J. Ali, and P. P. Yupapin, Multi Soliton Generation for Enhance Optical Communication, Applied Mechanics and Materials, 83, 2011, 136-140.

[50] J. Ali, I. S. Amiri, A. Afroozeh, M. Kouhnavard, M. Jalil, and P. Yupapin, Simultaneous dark and bright soliton trapping using nonlinear MRR and NRR, presented at the ICAMN, International Conference, Malaysia, 2010.

[51] J. Ali, I. S. Amiri, M. A. Jalil, F. K. Mohamad, and P. P. Yupapin, Optical dark and bright soliton generation and amplification, presented at the Nanotech Malaysia, International Conference on Enabling Science \& Technology, Kuala Lumpur, Malaysia, 2010.

[52] I. S. Amiri, M. H. Khanmirzaei, M. Kouhnavard, P. P. Yupapin, and J. Ali, Quantum Entanglement using Multi Dark Soliton Correlation for Multivariable Quantum Router, in Quantum Entanglement, A. M. Moran, Ed., New York: Nova Science Publisher, 2012 .

[53] A. Nikoukar, I. S. Amiri, and J. Ali, Secured Binary Codes Generation for Computer Network Communication, presented at the Network Technologies \& Communications (NTC) Conference, Singapore, 2010-2011.

[54] C. Tanaram, C. Teeka, R. Jomtarak, P. P. Yupapin, M. A. Jalil, I. S. Amiri, and J. Ali, ASK-to-PSK generation based on nonlinear microring resonators coupled to one MZI arm, Procedia Engineering, 8, 2011, 432-435.

[55] A. Afroozeh, I. S. Amiri, A. Samavati, J. Ali, and P. Yupapin, THz frequency generation using MRRs for THz imaging, in Enabling Science and Nanotechnology (ESciNano) Conference, Malaysia, 2012, 1-2.

[56] J. Ali, I. S. Amiri, A. Jalil, A. Kouhnavard, B. Mitatha, and P. Yupapin, Quantum internet via a quantum processor, presented at the International Conference on Photonics (ICP 2010), Langkawi, Malaysia 2010.

[57] I. S. Amiri, A. Afroozeh, I. N. Nawi, M. A. Jalil, A. Mohamad, J. Ali, and P. P. Yupapin, Dark Soliton Array for communication security, Procedia Engineering, 8, 2011, 417-422.

[58] N. J. Ridha, F. K. Mohamad, I. S. Amiri, Saktioto, J. Ali, and P. P. Yupapin, Soliton Signals and The Effect of Coupling Coefficient in MRR Systems, presented at the International Conference on Experimental Mechanics (ICEM), Kuala Lumpur, Malaysia, 2010.

[59] N. Suwanpayak, S. Songmuang, M. A. Jalil, I. S. Amiri, I. Naim, J. Ali, and P. P. Yupapin, Tunable and storage potential well s using microring resonator system for bio-cell trapping and delivery, in Enabling Science and Nanotechnology (ESciNano) Conference, 2010, 289-291.

[60] J. Ali, I. S. Amiri, M. A. Jalil, A. Afroozeh, M. Kouhnavard, and P. P. Yupapin, Multi-soliton generation and storage for nano optical network using nano ring resonators, presented at the ICAMN, International Conference, Prince Hotel, Kuala Lumpur, Malaysia, 2010 .

[61] J. Ali, M. A. Jalil, I. S. Amiri, and P. P. Yupapin, Effects of MRR parameter on the bifurcation behavior, presented at the Nanotech Malaysia, International Conference on Enabling Science \& Technology, Kuala Lumpur, Malaysia 2010. 
[62] I. S. Amiri, M. A. Jalil, F. K. Mohamad, N. J. Ridha, J. Ali, and P. P. Yupapin, Storage of Optical Soliton Wavelengths Using NMRR, presented at the International Conference on Experimental Mechanics (ICEM), Kuala Lumpur, Malaysia, 2010.

[63] M. Bahadoran, I. S. Amiri, A. Afroozeh, J. Ali, and P. P. Yupapin, Analytical Vernier Effect for Silicon Panda Ring Resonator, presented at the National Science Postgraduate Conference, NSPC, Universiti Teknologi Malaysia, 2011.

[64] A. Afroozeh, M. Kouhnavard, I. S. Amiri, M. A. Jalil, J. Ali, and P. P. Yupapin, Effect of Center Wavelength on MRR Performance, in Faculty of Science Postgraduate Conference (FSPGC), Universiti Teknologi Malaysia, 2010.

[65] J. Ali, K. Raman, M. Kouhnavard, I. S. Amiri, M. A. Jalil, A. Afroozeh, and P. P. Yupapin, Dark soliton array for communication security, presented at the AMN-APLOC International Conference, Wuhan, China, 2011.

[66] M. Kouhnavard, A. Afroozeh, M. A. Jalil, I. S. Amiri, J. Ali, and P. P. Yupapin, Soliton Signals and the Effect of Coupling Coefficient in MRR Systems, in Faculty of Science Postgraduate Conference (FSPGC), Universiti Teknologi Malaysia, 2010.

[67] C. Teeka, S. Songmuang, R. Jomtarak, P. P. Yupapin, M. A. Jalil, I. S. Amiri, and J. Ali, ASK to PSK Generation based on Nonl inear Microring Resonators Coupled to One MZI Arm, in International Conference on Enabling Science and Nanotechnology, EsciNano, 2011, 221-223.

[68] J. Ali, I. S. Amiri, M. A. Jalil, M. Hamdi, F. K. Mohamad, N. J. Ridha, and P. P. Yupapin, Proposed molecule transporter system for qubits generation, presented at the Nanotech Malaysia, International Conference on Enabling Science \& Technology, Malaysia 2010.

[69] J. Ali, M. Jalil, I. S. Amiri, A. Afroozeh, M. Kouhnavard, I. Naim, and P. Yupapin, Multi-wavelength narrow pulse generation using MRR, presented at the ICAMN, International Conference, Prince Hotel, Kuala Lumpur, Malaysia, 2010.

[70] I. S. Amiri, M. A. Jalil, F. K. Mohamad, N. J. Ridha, J. Ali, and P. P. Yupapin, Storage of Atom/Molecules/Photon using Optical Potential Wells, presented at the International Conference on Experimental Mechanics (ICEM), Kuala Lumpur, Malaysia, 2010.

[71] J. Ali, M. Kouhnavard, I. S. Amiri, A. Afroozeh, M. A. Jalil, I. Naim, and P. P. Yupapin, Localization of soliton pulse using nanowaveguide, presented at the ICAMN, International Conference, Prince Hotel, Kuala Lumpur, Malaysia, 2010.

[72] I. S. Amiri, A. Afroozeh, M. Bahadoran, J. Ali, and P. P. Yupapin, Up and Down Link of Soliton for Network Communication, presented at the National Science Postgraduate Conference, NSPC, Malaysia, 2011.

[73] D. Gifany, I. S. Amiri, M. Ranjbar, and J. Ali, Logic Codes Generation and Transmission Using an Encoding-Decoding System, International Journal of Advances in Engineering \& Technology (IJAET), 5(2), 2013, 37-45

[74] I. S. Amiri, A. Nikoukar, J. Ali, and P. P. Yupapin, Ultra-Short of Pico and Femtosecond Soliton Laser Pulse Using Microring Resonator for Cancer Cells Treatment, Quantum Matter, 1(2), 2012, 159-165.

[75] J. Ali, M. A. Jalil, I. S. Amiri, and P. P. Yupapin, Fast and slow lights via an add/drop device, presented at the ICEM, Legend Hotel, Kuala Lumpur, Malaysia, 2010.

[76] J. Ali, A. Afroozeh, I. S. Amiri, M. Hamdi, M. Jalil, M. Kouhnavard, and P. Yupapin, Entangled photon generation and recovery via MRR, presented at the ICAMN, International Conference, Prince Hotel, Kuala Lumpur, Malaysia, 2010.

[77] A. Afroozeh, I. S. Amiri, M. Kouhnavard, M. Jalil, J. Ali, and P. Yupapin, Optical dark and bright soliton generation and amplification, in Enabling Science and Nanotechnology (ESciNano) Conference, Malaysia, 2010, 259-263.

[78] J. Ali, M. A. Jalil, I. S. Amiri, A. Afroozeh, M. Kouhnavard, and P. P. Yupapin, Generation of tunable dynamic tweezers using darkbright collision, presented at the ICAMN, International Conference, Prince Hotel, Kuala Lumpur, Malaysia, 2010.

[79] J. Ali, M. Aziz, I. S. Amiri, M. Jalil, A. Afroozeh, I. Nawi, and P. Yupapin, Soliton wavelength division in MRR and NRR Systems, presented at the AMN-APLOC International Conference, Wuhan, China 2010.

[80] A. Afroozeh, M. Bahadoran, I. S. Amiri, A. R. Samavati, J. Ali, and P. P. Yupapin, Fast Light Generation Using Microring Resonators for Optical Communication, presented at the National Science Postgraduate Conference NSPC, Universiti Teknologi Malaysia, 2011.

[81] J. Ali, H. Nur, S. Lee, A. Afroozeh, I. S. Amiri, M. Jalil, A. Mohamad, and P. Yupapin, Short and millimeter optical soliton generation using dark and bright soliton, presented at the AMN-APLOC International Conference, Wuhan, China, 2010.

[82] F. K. Mohamad, N. J. Ridha, I. S. Amiri, J. A. Saktioto, and P. P. Yupapin, Effect of Center Wavelength on MRR Performance, presented at the International Conference on Experimental Mechanics (ICEM), Kuala Lumpur, Malaysia, 2010.

[83] J. Ali, A. Afroozeh, I. S. Amiri, M. Jalil, and P. Yupapin, Wide and narrow signal generation using chaotic wave, presented at the Nanotech Malaysia, International Conference on Enabling Science \& Technology, Kuala Lumpur, Malaysia, 2010.

[84] F. K. Mohamad, N. J. Ridha, I. S. Amiri, J. A. Saktioto, and P. P. Yupapin, Finesse Improvements of Light Pulses within MRR System, presented at the International Conference on Experimental Mechanics (ICEM), Kuala Lumpur, Malaysia, 2010.

[85] S. Saktioto, M. Hamdi, I. S. Amiri, and J. Ali, Transition of diatomic molecular oscillator process in THz region, presented at the International Conference on Experimental Mechanics (ICEM), Legend Hotel, Kuala Lumpur, Malaysia, 2010.

[86] A. Afroozeh, I. S. Amiri, M. Bahadoran, J. Ali, and P. P. Yupapin, Simulation of Soliton Amplification in Micro Ring Resonator for Optical Communication, Jurnal Teknologi (Sciences and Engineering), 55, 2012, 271-277.

[87] I. S. Amiri, G. Vahedi, A. Nikoukar, A. Shojaei, J. Ali, and P. Yupapin, Decimal Convertor Application for Optical Wireless Communication by Generating of Dark and Bright Signals of soliton, International Journal of Engineering Research \& Technology (IJERT), 1(5), 2012

[88] A. Nikoukar, I. S. Amiri, A. Shahidinejad, A. Shojaei, J. Ali, and P. Yupapin, MRR quantum dense coding for optical wireless communication system using decimal convertor, in Computer and Communication Engineering (ICCCE) Conference, Malaysia, 2012, 770-774.

[89] A. Afroozeh, I. S. Amiri, J. Ali, and P. P. Yupapin, Determination Of FWHM For Solition Trapping, Jurnal Teknologi (Sciences and Engineering), 55, 2012, 77-83.

[90] M. A. Jalil, I. S. Amiri, C. Teeka, J. Ali, and P. P. Yupapin, All-optical Logic XOR/XNOR Gate Operation using Microring and Nanoring Resonators, Global Journal of Physics Express, 1(1), 2011, 15-22.

[91] I. S. Amiri, A. Nikoukar, and J. Ali, Quantum Information Generation Using Optical Potential Well, presented at the Network Technologies \& Communications (NTC) Conference, Singapore, 2010-2011.

[92] S. Saktioto, J. Ali, M. Hamdi, and I. S. Amiri, Calculation and prediction of blood plasma glucose concentration, presented at the ICAMN, International Conference, Prince Hotel, Kuala Lumpur, Malaysia, 2010.

[93] J. Ali, C. Teeka, R. Jomtarak, P. Yupapin, M. Jalil, and I. Amiri, ASK-to-PSK generation based on nonlinear microring resonators coupled to one MZI arm, presented at the Nanotech Malaysia, International Conference on Enabling Science \& Technology, Kuala Lumpur, Malaysia, 2010.

[94] S. Saktioto, M. A. A. Fadhali, J. Ali, H. Shah, P. P. Yupapin, and I. S. Amiri, Power transient of time evolution for dynamic fusion fiber coupling monitoring, Optik, 2010.

[95] C. Teeka, S. Songmuang, R. Jomtarak, P. Yupapin, M. Jalil, I. Amiri, and J. Ali, ASK-to-PSK Generation based on Nonlinear Microring Resonators Coupled to One MZI Arm, in AIP Conference Proceedings, 2011, 221-223. 